\title{
Longevity of Cane Corso Italiano dog breed and its relationship with hair colour
}

\author{
Evžen Korec*, Ondřej Chalupa, Matyáš Hančl, Jana Korcová and Marie Bydžovská \\ Department of Genetics, ZOO Tábor, Dukelských hrdinů 19, Prague 7, 170 00, Czech Republic
}

\begin{abstract}
The Cane Corso Italiano belongs among the new dog breeds that were fully recognised by Federation Cynologique Internationale (FCI) in 2007. For the first time, this study describes a median lifespan using the data of 232 dogs of the Cane Corso Italiano breed collected from kennels and individual owners from 25 countries. The median lifespan of the whole examined group is 9.29 years (IQR 6.98-11.12, IQR = Interquartile Range). This paper is the first to describe the possible relationship between median lifespan and hair colour within one breed. The longest living group is formed by black brindle coloured dogs, with a median of 10.30 years (IQR 8.33-13.00), and brindle coloured dogs, with a median of 10.13 years (IQR 7.12-11.25). The median lifespan of black brindle dogs exceeded the overall median lifespan of all dogs by 1.01 year and the median lifespan of other colour dogs by 2.21 years. Our results suggest a possible way for a prolongation of age at death of the Cane Corso Italiano breed using appropriate breeding. The median lifespan of male Cane Corso Italiano dogs is 9.25 years (IQR 6.97-11.00) and female Cane Corso Italiano dogs 9.33 years (IQR 7.00-11.31). The statistical analysis using the Independent Samples Student's $t$ test confirmed that the lifespan of female dogs did not exceed the median lifespan of male dogs $(P>0.01)$.

Keywords: Cane Corso Italiano, Dog Breed, Kennel, Life Prolongation, Lifespan.
\end{abstract}

\section{Introduction}

The lifespan of most dog breeds has been described in the past (Adams et al., 2010; O’Neill et al., 2013). The most frequent causes of death, such as cancer, cardiac and urologic diseases and many others, have been described using statistical methods (Bonnett et al., 2005; Fleming et al., 2011). Young dogs commonly died from gastrointestinal and infectious causes whereas older dogs died of neurological and neoplastic causes (Fleming et al., 2011).

The median age at death described in the study of Adams et al. (2010), containing data on 15881 dogs (more than 150 breeds), was 11 years and 3 months (minimum 2 months, maximum 23 years and 5 months). The median age at death was significantly higher in small breeds (13.50-15.56) compared to large or giant breeds (3.83-7.46) (Adams et al., 2010).

The fact that smaller breeds, such as the Terrier, Beagle, Bearded Collie, Bichon Frise, Dachshund, Miniature Pinscher, Miniature Poodle, Toy Poodle and Whippet, lived longer and giant breeds, such as the Leonberger, Mastiff, Bloodhound, Irish Wolfhound, Deerhound and Bernese Mountain Dog, had a shorter lifespan has been confirmed in more studies (Bronson, 1982; Michell, 1999; Proschowsky et al., 2003; O’Neill et al., 2013).

A negative correlation has been observed between height and longevity and between weight and longevity (Greer et al., 2007). Longevity in crossbred dogs exceeded purebred dogs by 1.20 years (O'Neill et al., 2013). Lifelong maintenance of lean body mass and attenuated accumulation of body fat were key factors in achieving an exceptional lifespan in Labrador Retrievers (Adams et al., 2016).

Comparison of longevity in dogs seen at primary care practices with dogs seen at veterinary teaching hospitals showed a completely different age at death by the same breed (Waters, 2014). In this article, Waters predicts that there is a lot of room for innovation in canine longevity research. Female Rottweiler dogs tend to achieve an exceptional longevity more than males. Removal of ovaries during the first 4 years of life erased the female survival advantage (Waters et al., 2009).

The Cane Corso Italiano (Fig. 1) belongs to the new dog breeds fully recognized by FCI (Federation Cynologique Internationale) in 2007. The lifespan data of this breed have so far not been described using a well-defined study.

The objective of this study is to describe the lifespan of the Cane Corso Italiano. The colour of the Cane Corso Italiano may differ (black, black brindle, brindle, fawn, grey, grey brindle and others). The study also focuses on the relationship between lifespan and hair colour.

\section{Materials and Methods}

\section{Data collection}

More than 600 randomly chosen kennels and owners of the Cane Corso Italiano breed from all over the world were asked to fill in a questionnaire containing 
identifying such as name, sex, hair colour, age at death, cause of death. Data collected with stated cause of death as "poisoning" or "accident" were excluded from this study.

We obtained data on 232 deceased dogs from 73 kennels and individual owners from 25 countries (Australia, Belgium, Bosnia and Herzegovina, Bulgaria, Canada, Czech Republic, Estonia, France, Germany, Greece, Hungary, Israel, Italy, Latvia, Macedonia, Montenegro, Netherlands, Poland, Russia, Serbia, Slovenia, Spain, Turkey, Ukraine, USA).

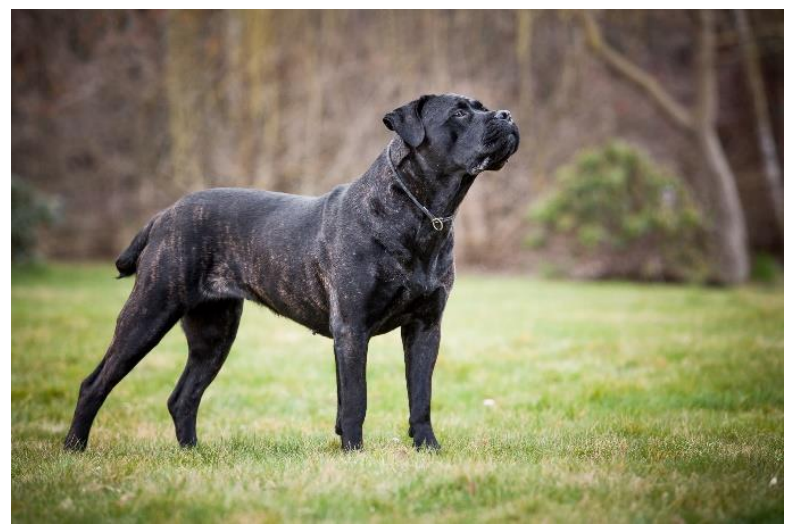

Fig. 1. Photograph of a Cane Corso Italiano dog (Koleta Atison, Evžen Korec's archive).

\section{Statistical methods}

Overall and colour-specific lifespan was reported using median, interquartile range (IQR), range and Analysis of variance (Iversen and Norpoth, 1987). Male and female lifespan was compared using the Independent Samples Student's t test (Rice, 2006). Normality of distribution was tested by the Shapiro-Wilk test (Shapiro and Wilk, 1965).

\section{Results and Discussion}

The collective sample of deceased dogs includes 114 $(50.22 \%)$ male and $113(49.78 \%)$ female Cane Corso Italiano dogs, 62 (26.72 \%) were black dogs, 38 (16.38 $\%)$ brindle dogs, 35 (15.08\%) black brindle dogs, 27 (11.64\%) fawn dogs, $26(11.21 \%)$ grey brindle dogs, $31(13.36 \%)$ grey dogs and $13(5.60 \%)$ other colour dogs.

The median lifespan and colour-specific median lifespan are summarized in Table 1. The overall (including all hair colour varieties) median lifespan is 9.29 years (IQR 6.98-11.12).

The longest living group is formed by black brindle coloured dogs with a median of 10.30 years (IQR 8.3313.00) and brindle coloured dogs with a median of 10.13 years (IQR 7.12-11.25). The shortest living group is other coloured dogs with a median of 8.09 years (IQR 5.46-9.16).

The data on female and male median lifespan are summarized in Table 2.
Table 1. Lifespan of different hair colour dogs of the Cane Corso Italiano breed.

\begin{tabular}{|c|c|c|c|c|c|}
\hline Colour & Median & IQR & Range & $\operatorname{Dog}_{s}(\mathrm{n})$ & $\%$ of total \\
\hline $\begin{array}{l}\text { Black } \\
\text { brindle }\end{array}$ & 10.30 & $\begin{array}{l}8.33- \\
13.00\end{array}$ & $\begin{array}{l}0.75- \\
16.00\end{array}$ & 35 & 15.10 \\
\hline Brindle & 10.13 & $\begin{array}{l}7.12- \\
11.25\end{array}$ & $\begin{array}{l}1.59- \\
14.00\end{array}$ & 38 & 16.40 \\
\hline $\begin{array}{l}\text { Grey } \\
\text { Brindle }\end{array}$ & 9.84 & $\begin{array}{c}7.00- \\
11.41\end{array}$ & $\begin{array}{l}3.60- \\
14.83\end{array}$ & 26 & 11.20 \\
\hline Fawn & 9.01 & $\begin{array}{l}7.73- \\
11.24\end{array}$ & $\begin{array}{l}2.59- \\
18.00\end{array}$ & 27 & 11.60 \\
\hline Black & 9.00 & $\begin{array}{l}6.14- \\
11.00\end{array}$ & $\begin{array}{l}0.42- \\
14.00\end{array}$ & 62 & 26.70 \\
\hline Grey & 9.00 & $\begin{array}{l}5.80- \\
10.28\end{array}$ & $\begin{array}{l}0.52- \\
17.00\end{array}$ & 31 & 13.40 \\
\hline Other & 8.09 & $\begin{array}{c}5.46- \\
9.16\end{array}$ & $\begin{array}{l}0.50- \\
11.00\end{array}$ & 13 & 5.60 \\
\hline $\begin{array}{l}\text { All } \\
\text { dogs }\end{array}$ & 9.29 & $\begin{array}{l}6.98- \\
11.12\end{array}$ & $\begin{array}{l}0.42- \\
18.00\end{array}$ & 232 & 100.00 \\
\hline
\end{tabular}

(Median): Median age at death (years); (IQR): Interquartile range; (n): number of dogs in the colour-specific group.

Table 2. Lifespan of female and male dogs of the Cane Corso Italiano breed.

\begin{tabular}{lccccc}
\hline Sex & Median & IQR & Range & Dogs (n) \% of total \\
\hline \multirow{2}{*}{ Female } & \multirow{2}{*}{9.33} & $\begin{array}{l}7.00- \\
11.31\end{array}$ & $\begin{array}{c}0.42- \\
16.00\end{array}$ & \multirow{2}{*}{113} & 50.22 \\
\multirow{2}{*}{ Male } & \multirow{2}{*}{9.25} & $\begin{array}{l}6.97- \\
11.00\end{array}$ & $\begin{array}{l}0.50- \\
18.00\end{array}$ & \multirow{2}{*}{114} & 49.78 \\
\hline
\end{tabular}

(Median): Median age at death (years); (IQR): Interquartile range; (n): number of dogs in the colour-specific group.

The median lifespan of male dogs is 9.25 years (IQR 6.97-11.00) and female dogs 9.33 years (IQR 7.0011.31). The statistical analysis using the Independent Samples T-test confirmed that lifespan of females did not exceed lifespan of males $(P>0.01)$. Statistical analysis using the Shapiro-Wilk test confirmed that the distributions in Fig. 2 are normal $(P>0.01)$.

Distribution patterns for age at death, interquartile range, range and median of all colour-determined groups are displayed in Fig. 2. Median age at death has been described for many dog breeds (Bronson, 1982; Proschowsky et al., 2003; Adams et al., 2010; O’Neill et al., 2013). The median lifespan of Cane Corso Italiano has so far not been determined using a welldefined study. For the first time, we described the median lifespan of the Cane Corso Italiano breed, which is 9.29 years. Comparing the median lifespan of other molossian type breeds (Hovawart: 12.92, Tibetan Mastiff: 11.92, Boxer: 10.25, Newfoundland: 9.67, Pyrenean Mountain Dog: 9.58, Bullmastiff: 7.46, Leonberger: 7.08, Bernard: 7.00, Mastiff: 6.83, Great Dane: 6.50, Bulldog: 6.29, Shar Pei: 6.29, Dogue de Bordeaux: 3.83, Neapolitan mastiff: 2.33) (Adams et al., 2010; O’Neill et al., 2013), the Cane Corso Italiano belongs to breeds with a higher median age at death (overall median: 9.29, median of black brindle coloured dogs: 10.30). 


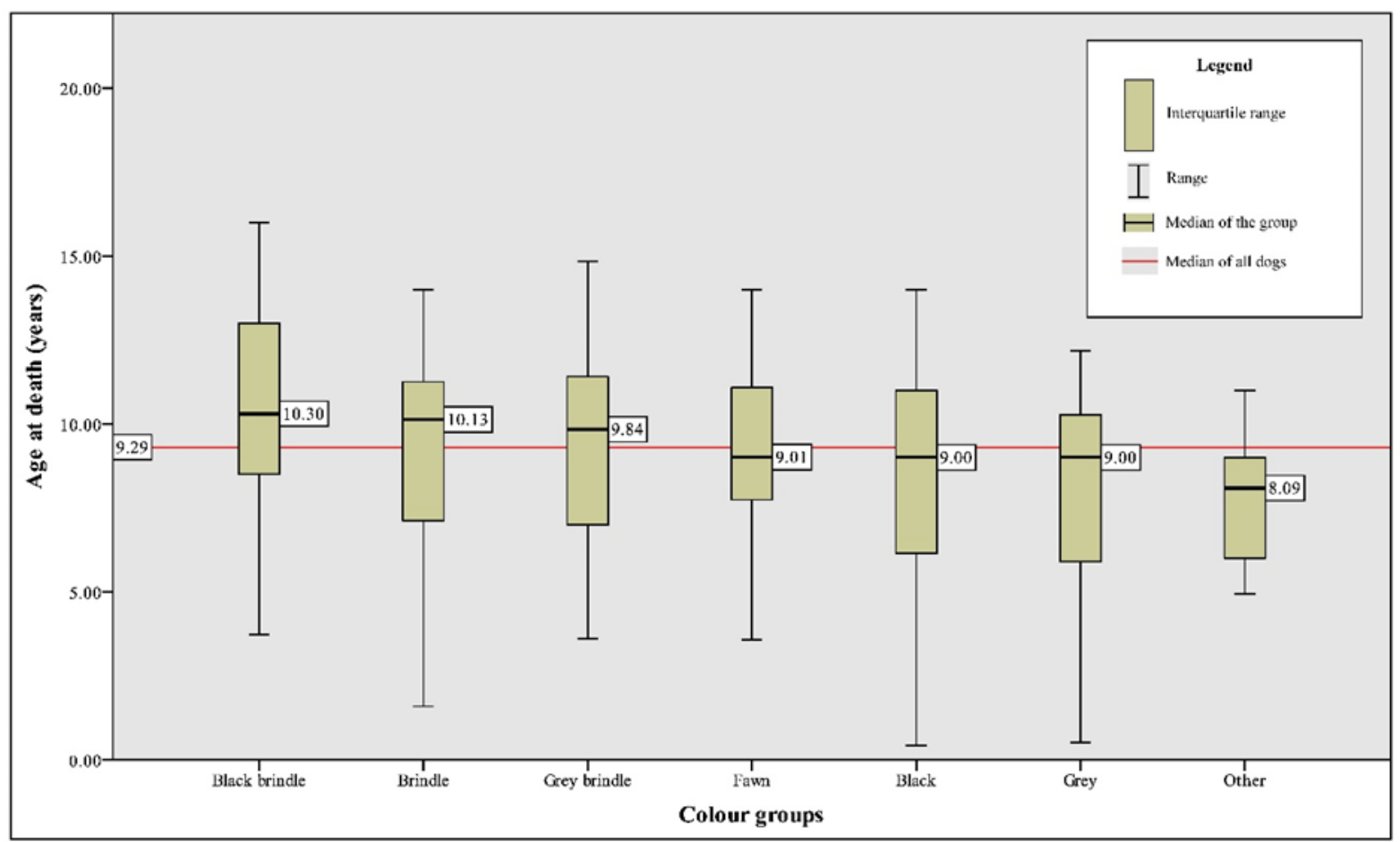

Fig. 2. Distribution pattern for age at death (years), IQR, range and median, $n=232$.

The possible relationship between median lifespan and hair colour within one breed has so far not been examined.

This paper describes the relationship between median lifespan and hair colour. The median age at death of the examined group of Cane Corso Italiano breed dogs is 9.29 years. The median lifespan of black brindle coloured dogs (10.30 years) exceeded the overall median lifespan by 1.01 year. The median lifespan of brindle dogs (10.13 years) and grey brindle dogs (9.84 years) also exceeded the overall median lifespan (9.29 years). This fact may suggest a relationship between brindle status (black brindle, brindle, grey brindle) and longevity. Examining this relationship will be the aim of our future study. Breeding programs should aim to reduce the prevalence of inherited disorders (Guandalini et al., 2016) and maximize the life prolongation.

Our results suggest a possible way to prolong age at death of the Cane Corso Italiano breed using appropriate breeding.

\section{Acknowledgements}

We wish to thank all the kennels and individual owners who provided us with the data for statistical analysis.

\section{Conflict of interest}

The authors declare that there is no conflict of interests.

\section{References}

Adams, V.J., Evans, K.M., Sampson, J. and Wood, J.L.N. 2010. Methods and mortality results of a health survey of purebred dogs in the UK. J. Small Anim. Pract. 51, 512-524.

Adams, V.J., Watson, P., Carmichael, S., Gerry, S., Penell, J. and Morgan, D.M. 2016. Exceptional longevity and potential determinants of successful ageing in a cohort of 39 Labrador retrievers: results of a prospective longitudinal study. Acta Vet. Scand. 58, 1-14.

Bonnett, B.N., Egenvall, A., Hedhammar, A. and Olson, P. 2005. Mortality in over 350,000 insured Swedish dogs from 1995-2000: I. Breed-, gender-, age- and cause-specific rates. Acta Vet. Scand. 46, 105-120.

Bronson, R.T. 1982. Variation in age at death of dogs of different sexes and breeds. Am. J. Vet. Res. 43, 2057-2059.

Fleming, J.M., Creevy, K.E. and Promislow, D.E.L. 2011. Mortality in North American Dogs from 1984 to 2004: An Investigation into Age-, Size-, and Breed-Related Causes of Death. J. Vet. Intern. Med. 25, 187-198.

Greer, K.A., Canterberry, S.C. and Murphy, K.E. 2007. Statistical analysis regarding the effects of height and weight on life span of the domestic dog. Res. Vet. Sci. 82, 208-214.

Guandalini, A., Di Girolamo, N., Santillo, D., Andreani, V., Corvi, R., Bandini, M. and Peruccio, C. 2016. Epidemiology of ocular disorders presumed to be inherited in three large Italian dog breeds in Italy. Vet. Ophthalmol. 19, 1-7. 
Iversen, G.R. and Norpoth, H.P. 1987. Analysis of Variance, Vol. 1. Second ed. Sage Publications, Lincoln, NE, USA, pp: 10-74.

Michell, A.R. 1999. Longevity of British breeds of dog and its relationships with sex, size, cardiovascular variables and disease. Vet. Rec. 145, 625-629.

O’Neill, D.G., Church, D.B., McGreevy, P.D., Thomson, P.C. and Brodbelt, D.C. 2013. Longevity and mortality of owned dogs in England. Vet. J. 198, 638-643.

Proschowsky, H.F., Rugbjerg, H. and Ersbøll, A.K. 2003. Mortality of purebred and mixed-breed dogs in Denmark. Prev. Vet. Med. 58, 63-74.
Rice, J.A. 2006. Mathematical Statistics and Data Analysis. Third ed. Thomson Brooks/Cole, Belmont, CA, USA, pp: 420-452.

Shapiro, S.S. and Wilk, M.B. 1965. An Analysis of Variance Test for Normality (Complete Samples). Biometrika 52, 591-611.

Waters, D.J. 2014. Longevity in pet dogs: Understanding what's missing. Vet. J. 200, 3-5.

Waters, D.J., Kengeri, S.S., Clever, B., Booth, J.A., Maras, A.H., Schlittler, D.L. and Hayek, M.G. 2009. Exploring mechanisms of sex differences in longevity: Lifetime ovary exposure and exceptional longevity in dogs. Aging Cell 8, 752-755. 